


\title{
Cold Neutron Research Facility
}

\author{
H. J. Prask
}

J. M. Rowe

Reactor Radiation Division

Materials Science and Engineering Laboratory National Institute of Standards and Technology

Gaithersburg, MD 20899

\section{March 1991}

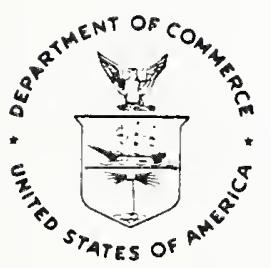

U. S. Department of Commerce Robert A. Mosbacher, Secretary National institute of Standards and Technology John W. Lyons, Director 


\section{The NIST Cold Neutron Research Facility}

H. J. Prask and J. M. Rowe

\section{Introduction}

In the last three decades, thermal neutrons have become an important probe of the properties of matter, particularly condensed matter. This usefulness arises from the intrinsic properties of the neutron, which can be summarized as follows:

The momentum of thermal neutrons corresponds to a de Broglie wavelength on the order of interatomic spacings in solids and liquids. From this, interference effects occur which provide information on the atomic arrangement and structure of the scattering system. The energy of thermal neutrons, $\sim 0.025 \mathrm{eV}$, is comparable to that of collective excitations in condensed matter so that in inelastic scattering, creation or annihilation of an excitation produces a large change in the energy of the neutron. In addition, the simultaneous measurement of energy and wavevector change provides the best means for the determination of dispersion curves in single crystals.

Although uncharged, the neutron has a magnetic moment, $-1.913 \mu_{\mathrm{N}}$, such that neutrons interact with unpaired electrons in magnetic atoms. Elastic scattering provides information on the magnetic structure; inelastic scattering probes the energies of magnetic excitations. Timedependent spin correlations are also elucidated in the scattering system through magnetic scattering. The absence of charge and the neutron mass (relative to the electron) dictate that neutrons are scattered primarily by nuclear forces which leads to penetrations in condensed matter generally about three orders-of-magnitude greater than x-rays of the same wavelength.

The neutron-nucleus interaction leads to sensitivity of neutrons to different isotopes of the same element in scattering so that, for example, hydrogen (which has a very high scattering cross section) is easily distinguishable from deuterium. Similarly, neutron absorption by a nucleus is isotope-sensitive so that chemical analysis is possible.

Since 1967 when the National Institute of Standards and Technology (NIST) Reactor (NBSR) achieved criticality, reactor-based research programs have increased enormously both in scope and in number of research participants (over 400 in FY 89). Currently operating at $20 \mathrm{MW}$ power and a peak thermal core flux of $4 \times 10^{14} \mathrm{n} / \mathrm{cm}^{2}-\mathrm{s}$, the NBSR is one of the top three research reactors in the country. Figure 1 shows a plan view of the reactor hall and experimental facilities, the capabilities of which have been recently summarized [1]. The research stations are allocated among the following activities:

- neutron scattering and diffraction

- neutron radiography

- trace analysis and depth profiling

- neutron standards development

- fundamental neutron physics

- long-term irradiations

- isotope production. 


\section{NIST REACTOR \\ Maln Floor Experimental Facllitlos}

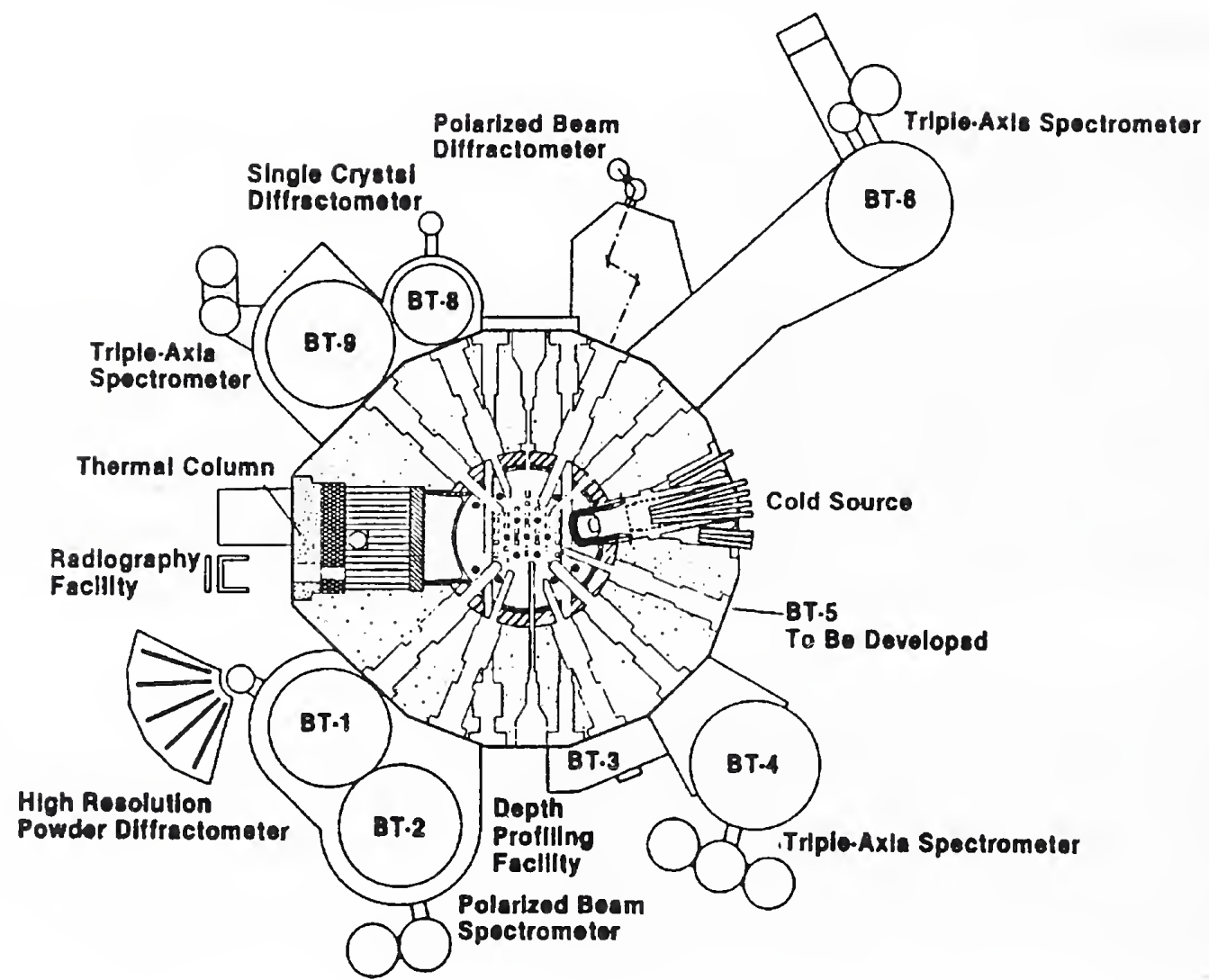

Figure 1. Reactor hall plan view.

Of these, trace analysis, neutron standards and dosimetry, and fundamental neutron physics are conducted at the reactor primarily by other segments of NIST; whereas, the permanent Reactor Radiation Division's staff's (22 Ph.D. scientists) interests include the following [2]:

Structural and spectroscopic studies of magnetic materials has been a long-term and very productive program. Current efforts have focussed on rare-earth compounds, amorphous magnets and spin glasses, superconductors, and magnetic bilayers. Another long-term program has been in the area of hydrogen in metals, including $\mathrm{H}$-dynamics at low concentrations and in metal crystals, and the details of hydrogen diffusion.

Molecular-system studies range from determination of crystal dynamics in condensed systems as complex as catalysts and military "energetic" materials, to characterization of phase transitions, and translation-rotation interaction in ionic crystals. Newer efforts in molecular systems include a special spectroscopic capability in which the dynamics of chemisorbed species on catalytic surfaces are characterized. Related to this is a relatively new effort in the area of intercalation compounds and pillared clays. 
Crystallographic studies have ranged from development of analytical techniques in single-crystal structure refinement and (powder) total-profile refinement to a host of structure determinations. The latter include ceramics-such as high- $\mathrm{T}_{C}$ superconductors and ionic conductors--alloys, zeolites, minerals, energetic, and biological materials. Structural studies focussed on the elucidation of phase transition mechanisms is a long-term, on-going program.

Small-angle neutron scattering (SANS) studies have encompassed a large variety of materials. Studies of polymer structure, including the interactions within diblock copolymers, have been of considerable interest. SANS results have also been important in determination of the conformation of biological macromolecular complexes in solution. Significant results have been obtained for structural materials and composites, including some elucidation of the role of bulk microstructure and porosity in materials durability and processing.

In the area of nondestructive evaluation (NDE), several programs are ongoing. A neutron radiography capability, in which the highly-thermalized thermal column beam is utilized, is well-established. At the same facility, an expanding program in neutron-induced autoradiography is under way, primarily focussing on works of art. Diffraction facilities are being utilized for texture characterization and residual stress determination for a variety of metallurgical and ceramic hardware.

In recent years, there has been an increasing interest in the use of "cold" neutrons (wavelength $>0.4 \mathrm{~nm}$; energy $<0.005 \mathrm{eV}$ ) for a variety of studies. As a result of their longer wavelengths, total reflection at interfaces makes it possible to build neutron guides, which can be used to transport intense beams over many tens of meters, and to focus beams down onto small spots. This, in turn, has opened up many new instrumentation possibilities and research opportunities, which are best characterized in terms of increased resolution in energy (by up to five orders of magnitude) and in the size of structures which can be determined. Cold neutrons have been used to study, for example, the conformation of polymers in solids and solutions, the size and distribution of precipitates in metallic alloys, the structure of composites, the early stages of metal creep and fatigue, microcracks in ceramics, densification of ceramics during processing, the structures of bioassemblies, thin films, interfaces, the coexistence of magnetic order and superconductivity, pore structure in microporous materials, tunneling in solids, phase transitions in solids, the behavior of molecules in solids and in solutions, and the diffusion of atoms in solids.

Activation analysis applications also benefit enormously through the enhancement of absorption cross sections as neutron energy decreases. In this area depth profiling is a powerful technique, in which the charged particles emitted when neutrons are absorbed by some elements are measured in order to characterize the depth distribution of elements near the surface of materials. In addition, by fully utilizing the special properties of cold neutrons to provide intense focussed beams, this technique can be extended by at least two orders of magnitude in sensitivity. This increase in capability will not only allow for more rapid profiling, but will make it possible to profile more elements (with lower cross sections) and also to simultaneously profile in the 
other two dimensions as well as in depth. Similar gains can be obtained for other types of materials analysis, such as prompt $\boldsymbol{\gamma}$-ray analysis, leading to greatly increased sensitivities.

Capabilities in neutron interferometry, neutron optics, and other important areas of fundamental physics research will also be enhanced.

In the following sections we present details of interest concerning neutron guides, cold sources, instrumentation, and research opportunities at the NIST Cold Neutron Research Facility.

\section{Background}

\subsection{Neutron Guides}

Many optical phenomena have been observed with neutrons; e.g., total reflection, refraction by a prism, and diffraction by a slit or ruled grating. These phenomena arise from interference between scattered waves and the waves of the incident beam and, in the case of refraction, have a number of applications.

The refractive index for neutrons is given by

$$
\mathrm{n}(\lambda)=1-\lambda^{2} \mathrm{a}_{\operatorname{coh}} \mathrm{N} / 2 \pi
$$

where $\mathrm{N}$ is the atomic density, $\mathrm{a}_{\mathrm{coh}}$ is the coherent scattering amplitude, and $\lambda$ is the neutron wavelength. Since $\mathrm{n}$ is smaller than one in most materials, total reflection with a critical angle

$$
\gamma_{C}(\lambda)=\{2(1-n)\}^{1 / 2}
$$

can be obtained with neutrons in exact analogy with the optical case. In the neutron case, however, $\mathrm{n} \sim 10^{-5}$ so that values for $\gamma_{\mathrm{C}}$ of $\sim 1^{\circ}$ are typical, as shown in table 1 . Since about 1962, this property has seen use in applications such as plane and bent neutron mirrors--including a bent mirror for focusing long-wavelength neutrons, and neutron "conducting" tubes, or guides [3]. The use of guides, in particular, has opened up enormous possibilities for research with neutrons.

Table 1. Values of $(1-n)$ and $\gamma_{c}$ for $1.0 \mathrm{~nm}$ neutrons

\begin{tabular}{lrrr} 
& $(1-\mathrm{n}) \times 10^{5}$ & $\gamma_{\mathrm{c}}$ (degrees) \\
\hline Glass & 6 & & 0.63 \\
$\mathrm{Cu}$ & & 10 & \\
$\mathrm{Ni}$ & 15 & 0.81 \\
58 & $\mathrm{Ni}$ & 21 & 0.99 \\
& & & 1.18 \\
\hline
\end{tabular}


The thermalized neutron beam exiting from a well-polished rectangular tube consists of two components: those neutrons passing straight through the tube aperture without undergoing any scattering, and those neutrons which reach the exit after at least one reflection at the tube walls. Neglecting beam losses (e.g., due to finite penetration, surface flaws) in the straight-through case the neutron current per unit energy interval is

$$
(\mathrm{dZ} / \mathrm{dE})_{0}=\mathrm{I}(\mathrm{E}) \mathrm{wh} \Omega=\mathrm{I}(\mathrm{E}) \mathrm{w}^{2} \mathrm{~h}^{2} / \mathrm{L}^{2}
$$

if $\gamma_{C}>w / L, h / L$ then in the total reflection case

$$
(\mathrm{dZ} / \mathrm{dE})_{\mathrm{r}}=\mathrm{I}(\mathrm{E}) 4 \gamma_{\mathrm{c}}^{2}(\mathrm{E}) \mathrm{wh}
$$

where $\mathrm{I}(\mathrm{E})$ is the incident flux density, $\Omega$ is the solid angle, and $\mathrm{L}, \mathrm{w}$, and $\mathrm{h}$ are the length, width and height, respectively, of the guide tube. The gain of intensity, $(\mathrm{dZ} / \mathrm{dE})_{\mathrm{r}} /(\mathrm{dZ} / \mathrm{dE})_{0}$, is $4 \gamma^{2}{ }_{\mathrm{C}} / \Omega$ and increases as $\mathrm{L}^{2}$; for $1.0 \mathrm{~nm}$ neutrons the totally reflected component equals the straightthrough component at $2.7 \mathrm{~m}$ for $\gamma_{C}=1^{\circ}$.

In straight guides the principal loss of intensity--other than that due to mechanical misalignment of guide sections--arises from attenuation of the neutron wave amplitude on penetration of the reflecting surface and macroscopic surface defects.

\subsection{Cold Sources}

As shown in figure 2, the actual distribution of neutron wavelengths from a reactor is Maxwellian, with a characteristic energy and wavelength dictated by the temperature of the moderator surrounding the fuel $\left(\mathrm{D}_{2} \mathrm{O}\right.$ at $\sim 40{ }^{\circ} \mathrm{C}$ in the NBSR case). With the increasing number of applications of longer wavelength (lower energy) neutrons, there has been--in recent years--a considerable effort made to provide more intense sources of these neutrons, by using neutron moderators cooled to low temperatures $(20-30 \mathrm{~K})--"$ cold" sources. This has the effect of shifting the spectrum as shown by the curves labelled $40 \mathrm{~K}$ and $60 \mathrm{~K}$ in figure 2 (which is only intended for illustrative purposes) and significantly increasing cold neutron intensity.

Since the first cold moderator was installed at a Harwell reactor in 1956, $\mathrm{CH}_{4}, \mathrm{H}_{2}, \mathrm{C}_{3} \mathrm{H}_{8}$, $\mathrm{D}_{2}$, and $\mathrm{D}_{2} \mathrm{O}$ have been the principal choices for cold source materials. A number of factors dictate the most effective cold source for a specific reactor environment. For example, the very large scattering cross section of hydrogen ( $\sim 80$ barns) leads to a short mean-free path and rapid moderation in a small volume. Furthermore, the finite absorption cross section, $\sim 1$ barn at $\lambda$ $=0.5 \mathrm{~nm}$, dictates that moderator thickness be small, e.g., $\leq 5 \mathrm{~cm}$ thick. Although this has the advantage of reduced nuclear heating and favorable refrigeration requirements, in general it also limits the number of beam tubes which can view the source. $\mathrm{A}_{2}$ moderator, as has been installed at the Institut Laue-Langevin (ILL) at Grenoble, France, requires a large volume to achieve moderation, but allows a number of beam tubes to view the source. The main drawback is the large heat load on the source, $\sim 18 \mathrm{~kW}$ for ILL, and the need to safely and reliably maintain this rate of cooling. 
Additional factors affecting cold source design include the character of the reactor spectrum at the position of the cold moderator and the size of the cold source cavity.

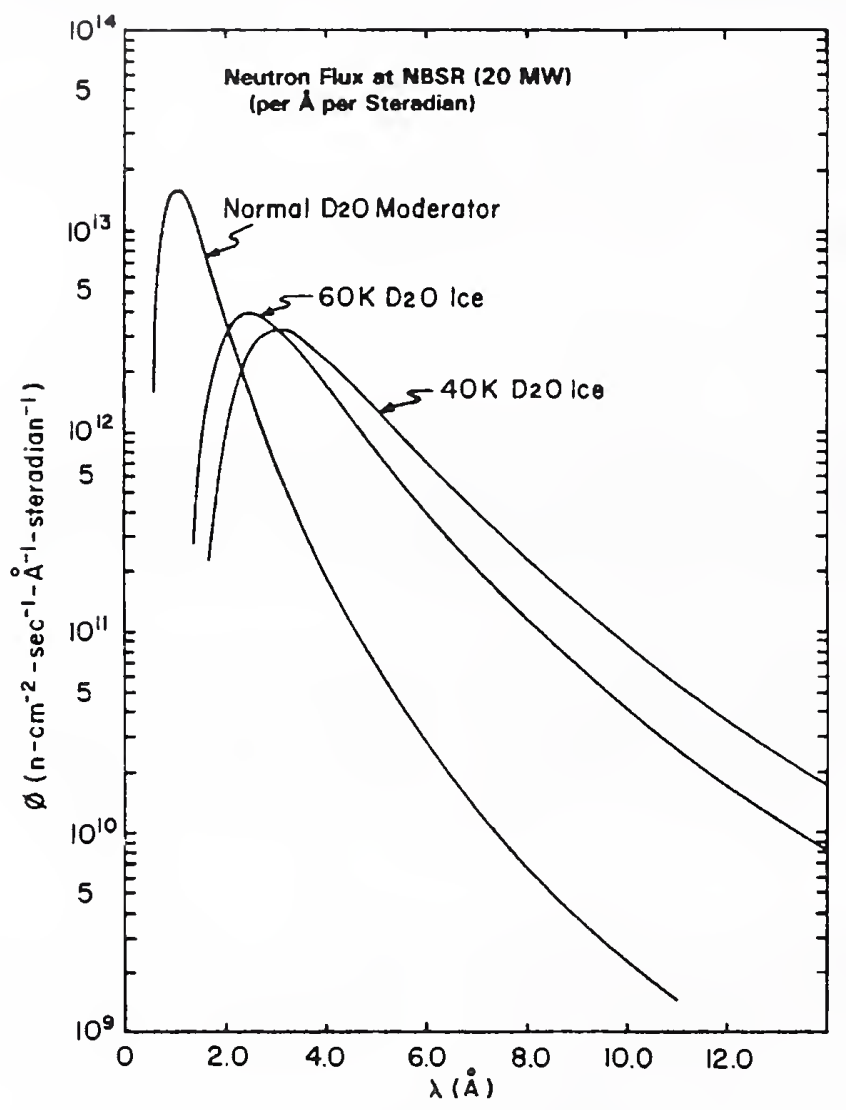

Figure 2. Maxwellian distribution.

\subsection{Cold Neutron Facilities}

Western Europe has not only been the site of the initial development of neutron guides and cold sources, it has been the unquestioned leader in the utilization of these devices in advanced neutron scattering facilities employing new instrumentation. In 1984 the United States had one operating cold source at Brookhaven National Laboratory (BNL), one under development (at then National Bureau of Standards (now NIST)), and no guide halls [4]. In contrast, at the ILL in France--the most extensively used research reactor in the world--16 of 27 instruments were on cold neutron guides. Since then a second cold source and second guide hall have been added to the ILL complex.

Even now after a center for cold neutron research was given the highest priority as a new capability at an existing facility [4], only one guide hall is under construction in the United States: the NIST Cold Neutron Research Facility (CNRF). In table 2, a recent compilation of cold sources is presented. [5] 
Table 2. Cold Neutron Sources ${ }^{a}$

\begin{tabular}{|c|c|c|c|c|}
\hline PLACE (COUNTRY) & SOURCE & POWER & MODERATOR $^{\mathrm{b}}$ & STATUS \\
\hline GRENOBLE (FR) & RHF/ILL & $57 \mathrm{MW}$ & $\mathrm{ID}_{2}$ & ${ }^{*} 1972 / 1985^{\mathrm{d}} /$ \\
\hline JÜLICH (GER) & FRJ 2 & $23 \mathrm{MW}$ & $1 \mathrm{H}_{2}$ & * $1972 / 1985^{\mathrm{d}}$ \\
\hline RISÖ (DEN) & PLUTO & $10 \mathrm{MW}$ & $\mathrm{gH}_{2}$ & * 1975 \\
\hline BROOKHAVEN/NY (USA) & HFBR & $60 \mathrm{MW}$ & $\mathrm{lH}_{2}^{2}$ & * 1977 \\
\hline SACLAY (FR) & ORPHEE & $14 \mathrm{MW}$ & $\mathrm{lH}_{2}^{2}(2)$ & * 1980 \\
\hline LENINGRAD (USSR) & VVR-M & $10 \mathrm{MW}$ & $1\left(\mathrm{H}_{2}+\mathrm{D}_{2}\right)$ & * 1985 \\
\hline RUTHERFORD (GB) & ISIS $^{\mathrm{e}}$ & --- & $\mathrm{gH}_{2}^{2}+\mathrm{ICH}_{4}$ & * 1985 \\
\hline ARGONNE/IL (USA) & IPNS $^{\mathrm{e}}$ & --- & $\mathrm{CH}_{4}^{2}(2 \mathrm{~s}+11)$ & * 1986 \\
\hline LOS ALAMOS/NM (USA) & LANSCE $^{\mathrm{e}}$ & --- & $1 \mathrm{H}_{2}$ & * 1986 \\
\hline KYOTO (JAPAN) & KUR & $5 \mathrm{MW}$ & $1 \mathrm{H}_{2}^{2}$ & * 1986 \\
\hline BOMBAY (INDIA) & DHRUVA & $100 \mathrm{MW}$ & $1 \mathrm{CH}_{4}$ & * 1986 \\
\hline GAITHERSB'G/MD (USA) & NBSR & $20 \mathrm{MW}$ & $\mathrm{sD}_{2} \mathrm{O}$ & $=1987$ \\
\hline TSUKUBA (JAPAN) & KENS- $1^{\mathrm{e}}$ & --- & $\mathrm{sCH}_{4}$ & $=1987$ \\
\hline GRENOBLE (FR) & RHF/ILL & $57 \mathrm{MW}$ & $1 D_{2}^{+}$ & $=1987^{\mathrm{d}}$ \\
\hline GEESTHACHT (GER) & FRG 1 & $5 \mathrm{MW}$ & $\mathrm{gH}_{2}$ & $=1987$ \\
\hline CHENGDO (CHINA) & HWRR & $15 \mathrm{MW}$ & $1 \mathrm{H}_{2}^{2}$ & $=1988$ \\
\hline BERLIN (GER) & BER 2 & $10 \mathrm{MW}$ & $\mathrm{gH}_{2}$ & $=1988$ \\
\hline TOKAI MURA (JAPAN) & JRR-3 & $20 \mathrm{MW}$ & $\mathrm{lH}_{2}^{2}$ & $=1988$ \\
\hline BUDAPEST (HUN) & KFKI & $15 \mathrm{MW}$ & $\mathrm{lH}_{2}^{2}$ & $=1989$ \\
\hline COLUMBIA/MO (USA) & MURR & $30 \mathrm{MW}$ & $\mathrm{IH}_{2}$ & $=1989$ \\
\hline DUBNA (USSR) & IBR-2g & & $1 \mathrm{H}_{2}^{2}$ ? & $>1989$ \\
\hline DJAKARTA (INDO) & MPR-30 & $30 \mathrm{MW}$ & $\mathrm{gH}_{2}$ & $>1990$ \\
\hline CHALK RIVER (CAN) & NRU & $135 \mathrm{MW}$ & $\mathrm{D}_{2} ?$ & $>1990$ \\
\hline VILLIGEN (SWITZ) & $\operatorname{SIN}-\mathrm{Q}^{\mathrm{e}}$ & & $?$ & $>1990$ \\
\hline
\end{tabular}

${ }^{\mathrm{a}}$ Based on ref. 5 ; sources $\geq 5 \mathrm{MW}$ power included here.

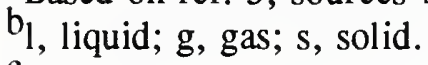

$c_{*}$, since; $=$, expected; $>$, later than.

$\mathrm{d}_{\text {modernized in } 1985 .}$

Accelerator source.

$\mathrm{f}_{\text {Second source, horizontal. }}$

gPulsed reactor. 


\section{The NIST Cold Neutron Research Facility}

\subsection{Cold Neutron Source and Guides}

The cold neutron source, which is installed in the NIST reactor, is shown in figure 3 . This source is a block of $\mathrm{D}_{2} \mathrm{O}-\mathrm{H}_{2} \mathrm{O}$ ice cooled to $30-40 \mathrm{~K}$ by recirculating helium gas. The gas is circulated by a compressor through a refrigerator capable of removing $1 \mathrm{~kW}$ of heat at $20 \mathrm{~K}$. The $\mathrm{D}_{2} \mathrm{O}$-cooled lead-bismuth shield removes most of the $\gamma$-ray heating before it reaches the cryostat and cold moderator. The ice block is $36 \mathrm{~cm}$ diam x $22 \mathrm{~cm}$ long, with an $18 \mathrm{~cm}$ diam $x 10 \mathrm{~cm}$ long reentrant hole to increase the cold neutron flux. An advanced liquid hydrogen moderator of comparable viewing area is now being designed for future installation.

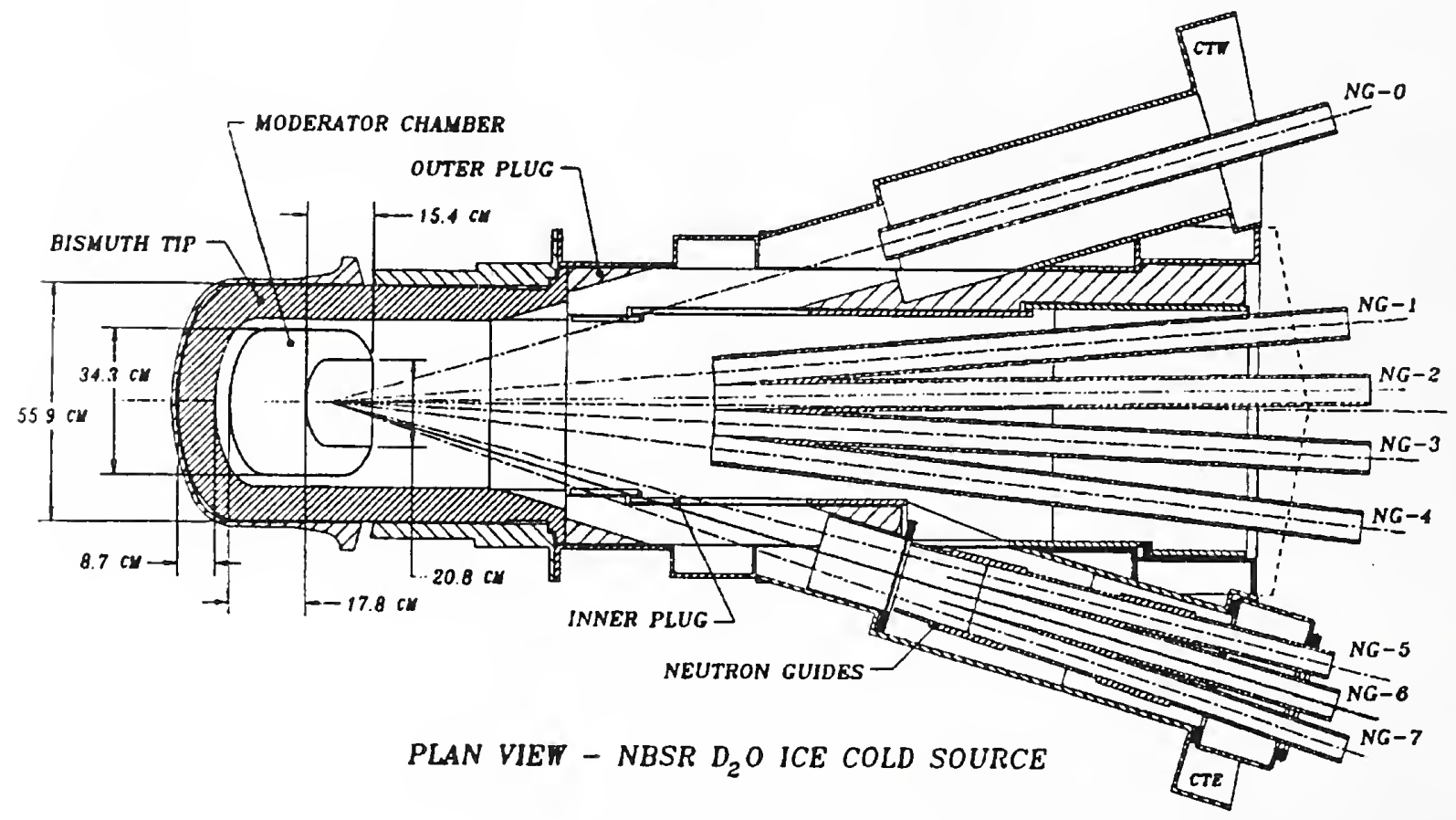

Figure 3. The cold source.

The present source was installed in August 1987 and became operational in October 1987. In anticipation that the performance of pure $\mathrm{D}_{2} \mathrm{O}$ could be improved by the addition of some $\mathrm{H}_{2} \mathrm{O}$, a series of tests were performed over a period of several months with different $\mathrm{H}_{2} \mathrm{O}$ concentrations. The optimum $\mathrm{H}_{2} \mathrm{O}$ concentration was found to be $7.5 \%$. Under this condition, the ratios of count rates measured with the cold source temperature at $30 \mathrm{~K}$ and with the source empty are plotted in figure 4 [6]. The measured gains increase from about 4.5 to 5.5 over the wavelength range from 0.5 to $1.2 \mathrm{~nm}$, and correspond to a $\sim 20 \%$ increase in flux compared to having pure $\mathrm{D}_{2} \mathrm{O}$ in the source. 


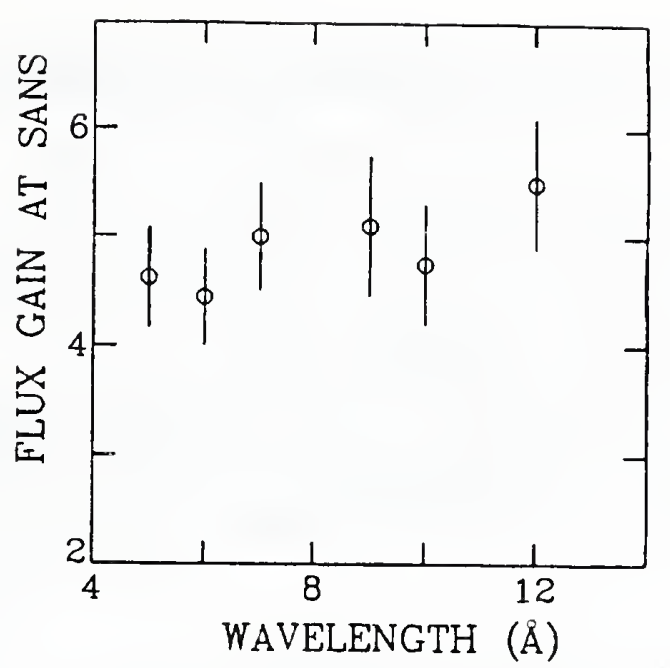

Figure 4. Data points are ratios of beam monitor count rates measured at the SANS instrument with the cold source at a temperature of $30 \mathrm{~K}$ (with $7.5 \% \mathrm{H}_{2} \mathrm{O}$ in the $\mathrm{D}_{2} \mathrm{O}$ ice) to those measured with the source empty $(1 \AA=0.1 \mathrm{~nm})$.

The cold source will be viewed by seven neutron guide tubes (NG 1-7) and an additional port for use inside the reactor hall (NG-0). The neutron guides, fabricated by Cilas-Alcatel of France, consist of a $100 \mathrm{~nm}$ coating of Ni deposited on optically flat glass, $15 \times 6 \mathrm{~cm}^{2}$ in cross section. The initial length of guides inside the reactor shielding will be coated with ${ }^{58} \mathrm{Ni}$ to increase the useable solid angle by $30 \%$ over normal nickel (see table 1). Although only three of the guides will use this isotope over their entire length, this arrangement allows later modification of the other guides without removal of the assembly from the reactor. The guides are evacuated to reduce neutron losses due to air scattering. The neutron guides then go through holes in the reactor confinement building wall, with shutters provided at the inside wall to allow work on the beam lines in the guide hall while the reactor is operating. Within the reactor hall and the guide hall, neutron and gamma-ray shielding will surround the guides.

\subsection{Neutron Guide Hall}

The neutron guide hall is located north of the reactor confinement building, and is $30.5 \mathrm{~m}$ wide $\mathrm{x} 61 \mathrm{~m}$ long, as shown in figure 5 . The roof is $14.6 \mathrm{~m}$ high in order to allow for a full span traveling crane of 20 ton capacity. The seven neutron guides coming from the cold source extend into the guide hall, and are supported on individual, vibration-isolated reinforced concrete beams supported on concrete piers. The guide hall floor is concrete slab on grade, supported by $95 \%$ compacted fill, with a floor loading of $2000 \mathrm{lb} / \mathrm{ft}^{2}$. The walls and crane rails are supported by augered cast-in-place concrete piles, decoupled from the floor to provide isolation. Services to individual instruments along the neutron beam lines are provided by floor trenches. The entire building is air conditioned for temperature and humidity control in both summer and winter. The walls are insulated panels, with continuous strips of insulated glass windows. Access to the guide hall from the existing building is by means of doors at the south end and on the east side. A truck access bay is located underneath the guide hall, with full crane access for easy movement of experimental equipment. 


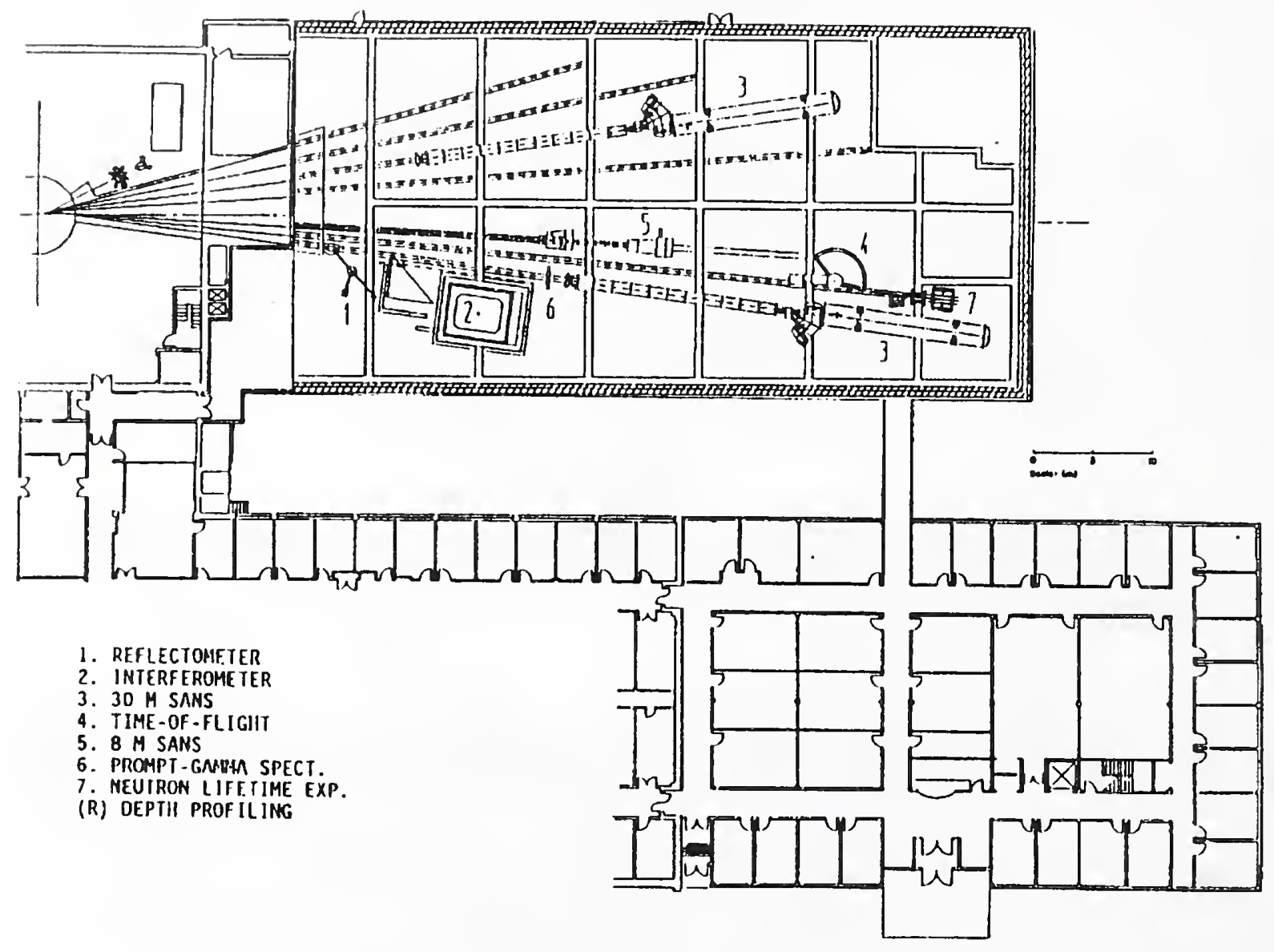

Figure 5. Partial plan view of reactor, guide hall, and offices.

Office and laboratory space for researchers of the facility is provided in an addition to an existing office/lab wing of the reactor building. This space provides 36 additional offices for researchers and staff, and 12 laboratories for sample preparation and equipment maintenance.

\subsection{The CNRF as a National Facility}

The completed number of research stations associated with the CNRF will be about 14 and will be of two types. NIST will develop 10 experimental stations for the use of the general U.S. materials science community. The Program Advisory Committee (PAC), appointed by NIST with members usually chosen from outside NIST, will allocate two-thirds of the available time on these stations on the basis of scientific merit of written proposals. Participating Research Teams (PRTs) will develop the additional stations. These PRTs might involve NIST although this will not be necessary. Proposals from prospective PRTs will be selected by the facility manager with the advice of the PAC. The PRTs will be responsible for the design, construction, and management of the facilities, which will entitle them to $3 / 4$ of the available instrument time. 
The remaining time will be allocated by the PAC in the usual manner. For all instrumental stations, instrument-responsible scientists will be designated to assist researchers in the performance of their experiments. As of January 1990, PRTs' agreements include the following:

Exxon Engineering and Research Corporation and the University of Minnesota are participating in the design and construction of a new high resolution small-angle neutron scattering (SANS) spectrometer.

The Organic and Electronic Materials Department of Sandia National Laboratories (SNL) has also entered into a long-term cooperative research agreement with the CNRF. SNL will provide partial funding for development and support costs of the new high-resolution time-of-flight and the new back-reflection spectrometer.

A neutron reflectometer is being developed by NIST in a PRT with IBM and the University of Minnesota.

In a special form of PRT, NIST and National Science Foundation (NSF) have announced plans to develop a Center for High Resolution Neutron Scattering (CHRNS) for research in chemistry, physics, biology, and materials science at the CNRF. The center, to be built around two state-of-the-art neutron research instruments to be designed and constructed by NIST with funding from NSF, will be managed as a national facility, open to use by U.S. universities, industries, and government agencies. The NSF-funded portion of CHRNS will be scheduled entirely by the PAC, aside from some time for instrument improvement, "breakthrough" experiments, and a small allotment of time for instrument-responsible scientists. The new instruments will be a second 30-m SANS spectrometer and one-half of a spin-polarized inelastic neutron scattering (SPINS) spectrometer.

Additional outside support and cooperation, already in place, includes a grant from Kodak for the chemical-analysis facilities, along with equipment funding for Fundamental Physics applications by DOE and the University of Sussex (U.K.).

\section{CNRF Experimental Facilities}

\subsection{First-Phase Instrumentation}

The first stage of the neutron guide installation will include the three guides that run along the east side of the guide hall, as indicated in the lower portion of figure 6 . The remaining four guides will be installed later, possibly at the same time as the new cold source. This schedule has been chosen to minimize reactor down time, while allowing for an orderly development of the full complement of instruments. 


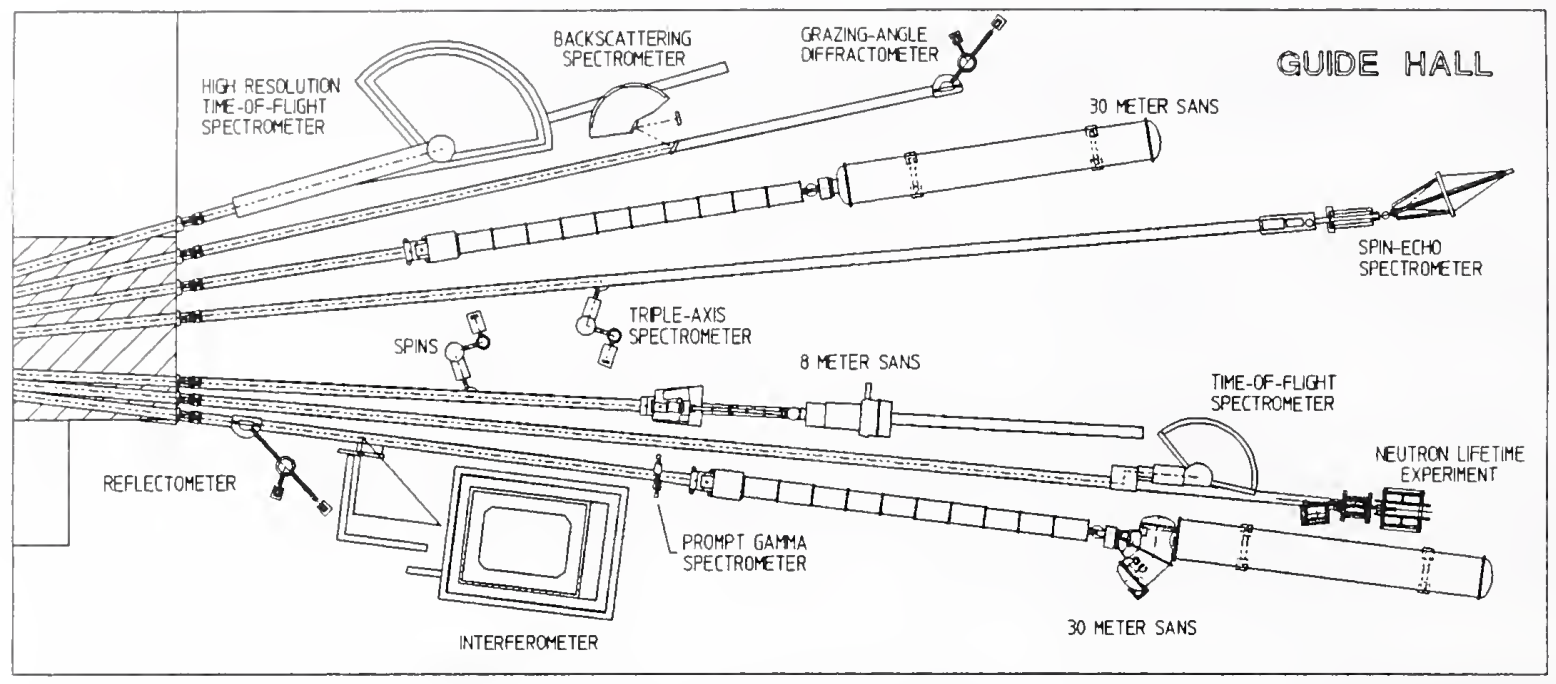

Figure 6. Guide hall floor plan.

\subsubsection{The NIST/Exxon/University of Minnesota 30-m SANS [7]}

This instrument, being developed jointly by NIST, the Exxon Research and Engineering Co., and the University of Minnesota, extends the measurement range and sensitivity of the NIST 8-m SANS instrument (Section 4.1.2) in both the small and intermediate angle regions, and, in addition, provides exceptional flexibility in optimizing beam intensity and resolution to meet the requirements of a particular measurement. The Q-range of the instrument extends from 0.01 $\mathrm{nm}^{-1}$ to nearly $10 \mathrm{~nm}^{-1}$ which enables structural features in materials ranging from roughly .5 to nearly $500 \mathrm{~nm}$ to be studied. This wide Q-range is achieved through the use of two large 2D position-sensitive detectors (see Fig. 7); a primary detector that moves axially within the cylindrical portion of the evacuated post-sample flight to vary the sample-to-detector distance continuously from 4 to $15 \mathrm{~m}$, and a second detector that moves along a circular arc (over a 40 degree range) at a fixed distance of $2 \mathrm{~m}$ from the sample. Flexibility in beam collimation is achieved by incorporating eight neutron guide sections in the $15-\mathrm{m}$ long pre-sample flight path that can be easily shifted in or out of the beam to change the effective source-to-sample distance in $1.5 \mathrm{~m}$ increments from 3 to $15 \mathrm{~m}$. A mechanical rotating velocity selector with variable speed and pitch provides the capability to vary both the wavelength and wavelength resolution of the beam over a wide range.

This instrument will commence operation using pinhole collimation and the primary detector in the Spring of 1991. The second detector, a high count rate detector of the ILL-type, is expected to be installed in 1992. Meanwhile, development work continues on two novel components for this instrument, which if successful will significantly expand its measurement capabilities. These are a Fe/Si supermirror array for polarizing the incident beam, and a doubly curved, grazing incidence mirror (to replace the pinhole collimation and increase the flux on the sample) to focus the beam onto the detector. The characteristics and expected performance of the instrument are summarized in table 3. 


\section{NIST / EXXON / UNIVERSITY OF MINNESOTA SANS SPECTROMETER}

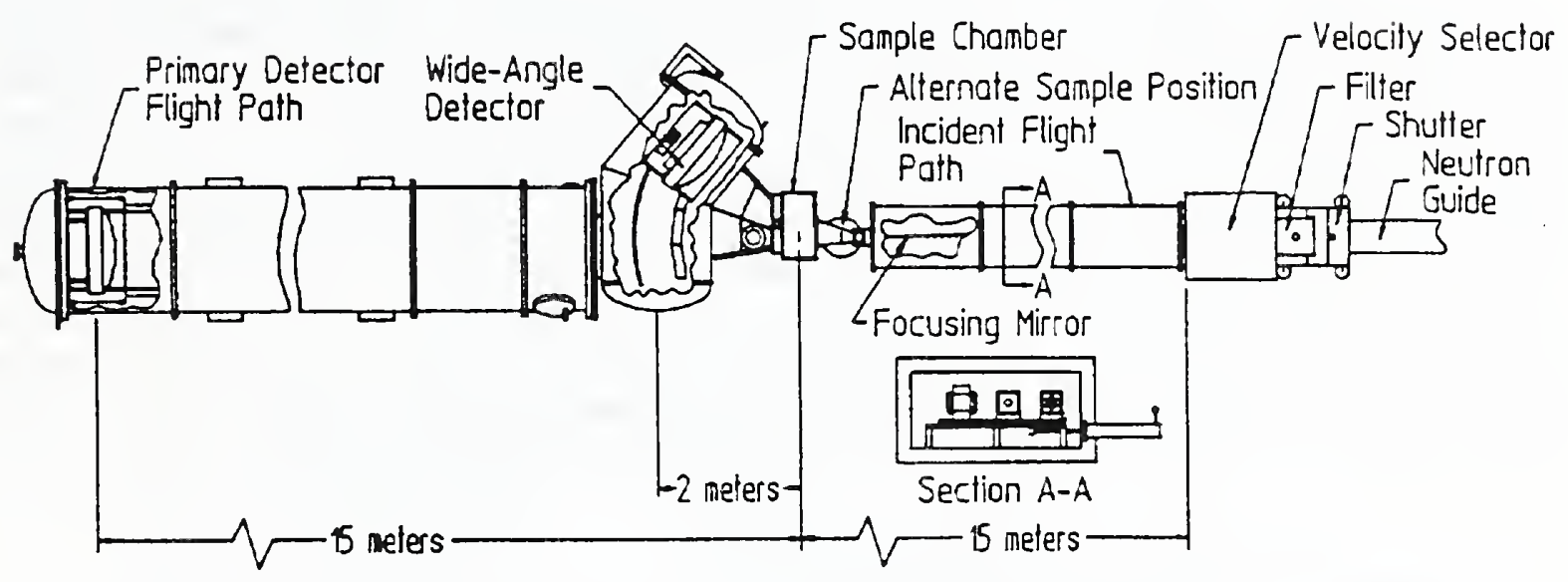

Figure 7. Schematic of the $30-\mathrm{m}$ SANS.

Table 3. NIST/Exxon/U. Minn. 30-m SANS spectrometer

Source:

Monochromator:

Wavelength range:

Wavelength resolution:

Source-to-sample distance:

Sample-to-detector distance:

Collimation options:

Sample size:

Q-range:

Size regime:

Detectors:

Polarized beam:

Ancillary equipment:
Characteristics and Projected Performance

neutron guide (NG-7), $5 \times 5 \mathrm{~cm}^{2}$ source area

mechanical velocity selector with variable speed and pitch

0.5 to $2.0 \mathrm{~nm}$

$10 \%$ to $25 \% \Delta \lambda / \lambda$ (FWHM)

3.0 to $15 \mathrm{~m}$ in $1.5 \mathrm{~m}$ steps via insertion of neutron guide segments primary detector -4 to $15 \mathrm{~m}$ continuously variable. secondary detector - $2 \mathrm{~m}$ (fixed), angular range from 0 to $40^{\circ}$ simple pinhole, multiple converging pinholes or grazing incidence focusing mirror

0.5 to $2.5 \mathrm{~cm}$ diam

0.01 to $10 \mathrm{~nm}^{-1}$

0.5 to $500.0 \mathrm{~nm}$

$2,65 \times 65 \mathrm{~cm}^{2}{ }^{3} \mathrm{He}$ position-sensitive proportional counters $\left(1 \mathrm{~cm}^{2}\right.$ resolution) optional via insertion of supermirror transmission polarizer automatic multi-specimen sample changer with temperature control from $-10^{\circ}$ to $200{ }^{\circ} \mathrm{C}$

\begin{tabular}{|c|c|c|c|c|c|}
\hline $\begin{array}{l}\text { Flux at } \\
\text { Sample } \\
\text { vs } Q_{\text {min }}\end{array}$ & $\begin{array}{l}\mathrm{Q}_{\min } \\
\mathrm{nm}^{-1} \\
0.01 \\
0.04 \\
0.1\end{array}$ & $\begin{array}{l}\text { present } \\
\text { source } \\
\mathrm{n} / \mathrm{cm}^{2} \text {-sec } \\
2 \times 10^{3} \\
6 \times 10^{4} \\
6 \times 10^{5}\end{array}$ & $\begin{array}{l}\text { improved } \\
\text { source } \\
n / \mathrm{cm}^{2}-\mathrm{sec} \\
4-6 \times 10^{3} \\
1-2 \times 10^{5} \\
1-2 \times 10^{6}\end{array}$ & $\begin{array}{l}\text { imp. source } \\
\& \text { focusing } \\
\mathrm{n} / \mathrm{cm}^{2}-\mathrm{sec} \\
1-2 \times 10^{4} \\
2-4 \times 10^{5} \\
1-2 \times 10^{6}\end{array}$ & $\begin{array}{l}\text { ILL D } 11^{\mathrm{a}} \\
(80 \mathrm{~m}) \\
\mathrm{n} / \mathrm{cm}^{2}-\mathrm{sec} \\
1 \times 10^{4} \\
2 \times 10^{5} \\
1.5 \times 10^{6}\end{array}$ \\
\hline
\end{tabular}

${ }^{\mathrm{a}}$ ILL Facilities Guide 


\subsubsection{NIST 8-m SANS Spectrometer}

This SANS spectrometer is 8-m long and is installed on NG-5. The instrument utilizes a mechanical velocity selector and pinhole collimation to provide a continuous incident beam whose wavelength is variable from 0.5 to $2.0 \mathrm{~nm}$. The neutron detector is a $65 \times 65 \mathrm{~cm}$ positionsensitive proportional counter which pivots about the sample position to extend the angular range of the spectrometer. The low angle limit of the instrument (see table 4) is achieved with a multiple-beam converging pinhole collimation system. A 50-cm diam sample table accepts standard cryostats, furnaces and electromagnets as well as a sample chamber which houses a temperature-controlled multiple sample changer. The instrument has a dedicated microcomputer which is networked to an interactive color graphics terminal with specialized software to provide rapid imaging and analysis of data from the two-dimensional detector. The instrument is suitable for the study of structural and magnetic inhomogeneities in materials in the 1 to $100-\mathrm{nm}$ range.

Table 4. NIST 8-m SANS spectrometer

Total Length:

Wavelength:

Collimation:

Sample Size:

Sample-to-Detector

Distance:

Q-range:

Neutrons on Sample and Minimum Q:

Detector:

Sample Environment:

Data Acquisition System:
$8 \mathrm{~m}$

variable from 0.5 to $2.0 \mathrm{~nm}, 25 \%$ wavelength resoluton (FWHM)

single pair of pinholes or 7 beam converging pinhole collimation

5 to $20 \mathrm{~mm}$

2.0 or $3.5 \mathrm{~m}$

0.025 to $5.0 \mathrm{~nm}^{-1}$

$1 \times 10^{6} \mathrm{n} / \mathrm{sec}\left(0.15 \mathrm{~nm}^{-1}\right)$

$2 \times 10^{4} \mathrm{n} / \mathrm{sec}\left(0.04 \mathrm{~nm}^{-1}\right)$

$65 \times 65 \mathrm{~cm}$ position-sensitive counter with

$1 \mathrm{~cm}$ resolution

temperature-controlled multiple sample changer

( $-10^{\circ}$ to $\left.200^{\circ} \mathrm{C}\right)$, magnetic field (0 to $\left.15 \mathrm{Kgauss}\right)$, cryostats and furnaces

dedicated minicomputer networked to VAX $11 / 750$ with interactive color graphics display

\subsubsection{Medium Resolution Time-of-Flight Spectrometer}

The NIST medium-resolution time-of-flight (TOF) spectrometer is most-suited for quasielastic and low-energy inelastic neutron scattering studies. When installed on the cold source in the reactor hall, it was used extensively for a variety of experimental studies including the elucidation of diffusive motions in molecular solids and the characterization of the dynamics of adsorbed or included molecular species (details in table 5.) Monochromated neutrons $(\lambda=0.23-0.61 \mathrm{~nm})$ are produced by double Bragg reflection from two pyrolytic graphite (002) crystals. Using the (004) reflection extends the wavelength range to $0.115 \mathrm{~nm}$. Double reflection allows for a fixed sample position independent of the incident neutron energy and reduces the fast-neutron background contributions from the primary beam by shifting the monochromated beam axis away 
from the primary beam axis. After monochromation, fast-neutron and higher-order contamination is removed using either a pyrolytic graphite filter (typically for $\lambda=0.243,0.235$, and $0.171 \mathrm{~nm}$ ) or a liquid-nitrogen-cooled Be filter (typically for $\lambda>0.408 \mathrm{~nm}$ ). The beam is subsequently pulsed with a curved-slit Fermi chopper before scattering off the sample. The 98 ${ }^{3}$ He detectors are radially located $2.31 \mathrm{~m}$ from the sample encompassing an angular scattering range of $2 \theta=-20^{\circ}-140^{\circ}$. The spectrometer is controlled with a dedicated CAMAC-interfaced $\mu$ VAX computer. A TOF interface encodes the time and position of each detected neutron for subsequent recording by the CAMAC histogram memory. Contents of the histogram memory are periodically transferred to the $\mu \mathrm{VAX}$ computer and added to data from previous transfers. This updated data can then be analyzed with the appropriate TOF software routines available.

Table 5. Details of Time-of-flight spectrometer in reactor hall

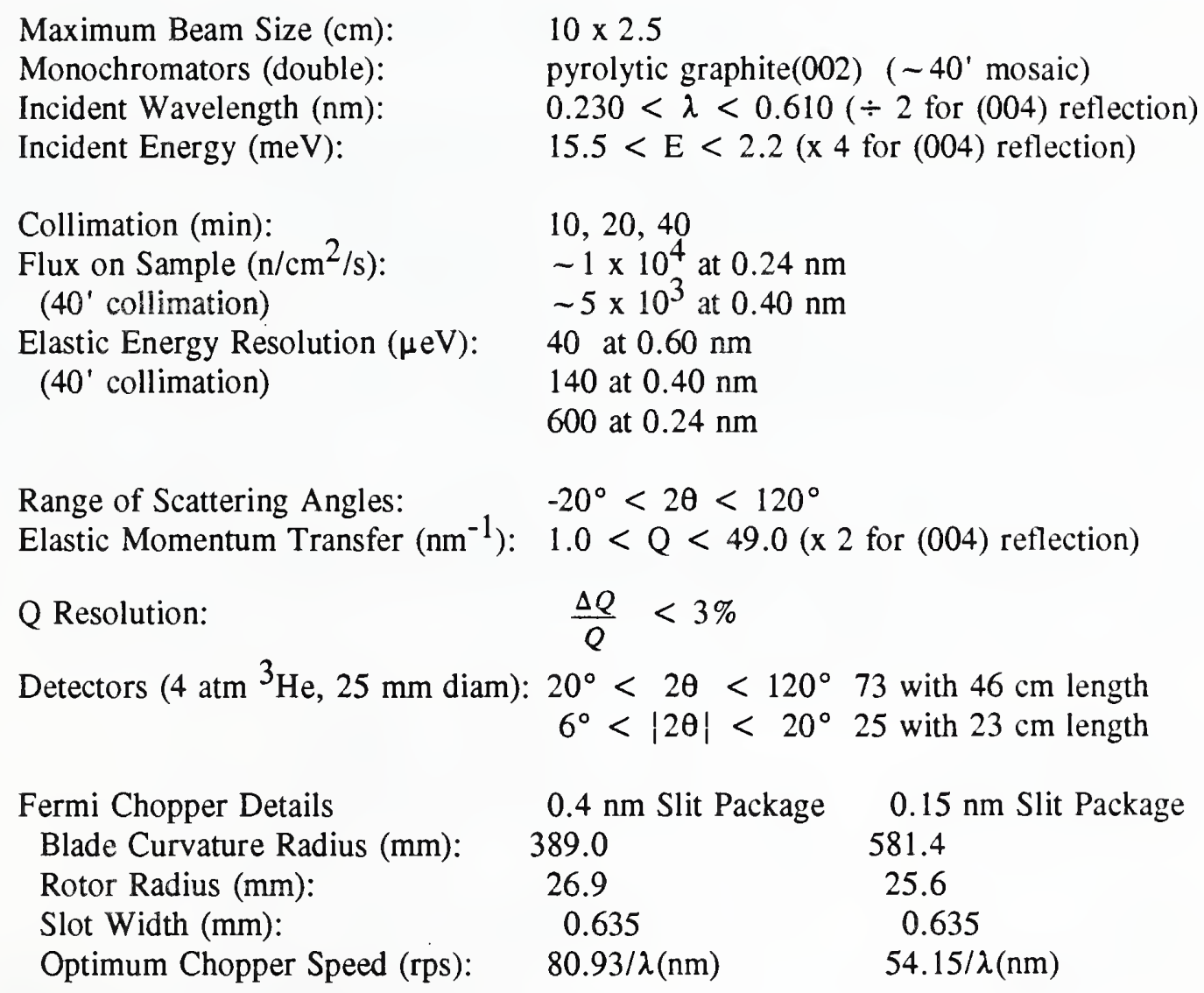

The TOF spectrometer will be located on NG-6. Work is in progress for upgrading the spectrometer at this time to (i) increase the neutron flux at the sample position for all wavelengths and (ii) mitigate the effects of parasitic scattering (from cryostat shielding, etc.) on the sample spectrum. The double monochromators will be increased in size to match the large $15 \times 6-\mathrm{cm}^{2}$ guide cross section. In addition, unlike the previous arrangement, the second monochromator will be vertically focussing onto the sample position. Vertical focussing is optimized when the vertical mosaic spread is minimized. Yet, for an isotropic mosaic spread, this minimized FWHM in the horizontal direction leads to an unnecessarily small wavelength spread and a subsequent 
decreased intensity on the sample. Hence, to gain maximum benefit from vertical focussing while still maintaining a desirably broad horizontal mosaic spread, both monochromators will possess an anisotropic mosaic distribution, 25' FWHM in the vertical direction and 40' $-50^{\prime}$ FWHM in the horizontal direction. This is being accomplished by using two layers of $\mathrm{PG}(002)$ crystals, each layer possessing a $25^{\prime}$ mosaic, but staggered horizontally with $20^{\prime}-25^{\prime}$ angular offset. Parasitic scattering will be mitigated by the installation of an oscillating radial collimator centered on the sample position and located between the sample and the detectors. In addition, the angular scattering range will be altered to $0^{\circ}<2 \theta<140^{\circ}$.

\subsubsection{The NIST/IBM/U. Minn Neutron Reflectometer}

In the past 10 years there has been growing interest in a variety of surface sensitive techniques including, most recently, neutron reflection from surfaces. A program has been initiated in neutron reflectivity measurements on a variety of surfaces and interfaces using a modified triple-axis spectrometer [8]. From this, methods and techniques have been developed to be used in the new reflectometer now being designed for installation in the guide hall. The design goal for this new instrument is the ability to do measurements of reflectivities of order $5 \times 10^{-7}$. The spectrometer will use a pyrolytic graphite crystal to both monochromate and vertically deflect the neutron beam onto a horizontal sample. This configuration will allow the measurement of reflectivities of liquid surfaces. The instrument will have two detectors--one at small angles to measure specular reflectivities, and another capable of scanning a large angular range in order to perform surface diffraction measurements. Independent movement of both sample and detector will be provided to allow measurement of off-specular scattering.

Some of the important instrumental parameters are listed in table 6.

Table 6. Reflectometer characteristics

Monochromator:

Wavelength range:

Wavelength resolution:

Beam size (continuously variable):

$Q$ range:

$\mathrm{Q}$ resolution:

Polarized beam:

Monochromator-to-sample distance:

Sample-to-detector distance

a) for reflectivity detector:

b) for grazing incidence diffraction detector:

Angular range for grazing incidence diffraction detector:
Pyrolitic graphite

$0.235 \mathrm{~nm}$ and $0.404-0.55 \mathrm{~nm}$

$1 \%$ to $2 \% \Delta \lambda / \lambda$

$.05 \times 50 \mathrm{~mm}$ to $2 \times 50 \mathrm{~mm}$

0.03 to $4 \mathrm{~nm}^{-1}$

Variable with slits from .02 to $.15 \Delta \mathrm{Q} / \mathrm{Q}$ Both initial and reflected beam polarized by multilayer transmission polarizers

$2 \mathrm{~m}$

$2 \mathrm{~m}$

$1.5 \mathrm{~m}$

$5^{\circ}-140^{\circ}$ 


\subsubsection{The Cold Neutron Depth-Profiling (NDP) Facility [9]}

NDP determines distribution of isotopic concentrations vs. depth within the first few micrometers of a surface. This is achieved by energy analysis of the prompt charged particles emitted following neutron capture--for which energy loss vs. path length is known. The instrument is operational. It includes a new $61 \mathrm{~cm}$ diam stainless-steel sample chamber, vacuum system, detectors, electronics, and data acquisition system. The new depth-profiling chamber is capable of operating at UHV pressures and incorporates many design features that enhance the capabilities that currently exist at the thermal depth-profiling instrument in the reactor hall. The chamber has an X-Y positioning system that will allow computer-controlled scanning of up to $15 \times 15 \mathrm{~cm}^{2}$ samples. The computer is also capable of rotating both the sample and the detectors to adjust the sensitivity for depth-profiling. The ability to use time-of-flight depth profiling techniques has also been incorporated into the chamber design. An electron gun for in-situ surface etching of samples will also be available.

The cold neutron beam at NG-0, inside the reactor hall, is filtered by $13.5 \mathrm{~cm}$ of singlecrystal sapphire to remove most of the fast neutrons. A thermal equivalent neutron fluence rate at the sample position of $1.6 \times 10^{9} \mathrm{n} / \mathrm{cm}^{2}-\mathrm{s}$ with a cadmium ratio of greater than $10^{3}$ has been measured. The peak energy of the beam is calculated to be $5.6 \mathrm{meV}$, which--for a $1 / \mathrm{v}$ cross section reaction--gives an effective cross section of 1.9 times the thermal value. This yields a sensitivity about 20 times that of the present thermal neutron facility particle detectors of the same efficiency. Pancake type uranium fission chambers are used for monitoring the neutron fluence.

A second chamber is being designed that will be placed downstream from the primary chamber. This will have a computer-controlled sample-changing capability for processing of batches of study materials. While this chamber will be less sophisticated than the primary, it will allow higher sample throughput for routine analyses. This chamber will also be operated at UHV pressures and in-situ surface etching may also be available.

Instrument characteristics are summarized in table 7.

Table 7. Comparison with present thermal NDP facility

$$
\text { BT-3 Cold Beam }
$$

$\begin{array}{lll}\text { Flux dens. } & 6 \times 10^{8} & \sim 1 \times 10^{9} \\ \text { Peak energy } & 22.5 \mathrm{meV} & \sim 5.6 \mathrm{meV} \\ \text { 10 }_{\mathrm{B} \text { sigma }} & 3404 \mathrm{barns} & \sim 5700 \mathrm{barns} \\ \text { Rel. sens. } & 1 & >20 \\ \text { Gamma dose } & 400 \mathrm{mR} / \mathrm{h} & \text { few } \mathrm{R} / \mathrm{h}\end{array}$




\subsubsection{Prompt-Gamma Activation Analysis (PGAA) Spectrometer [10]}

PGAA gives simultaneous nondestructive determination of many major, minor, and trace elements in a variety of bulk matrices. The sample is irradiated with a beam of neutrons. The constituent elements of the sample absorb some of these neutrons and emit prompt gamma rays which are measured with a high-resolution gamma-ray spectrometer. The energies of these gamma rays give qualitative identification of the neutron-capturing elements, and the intensity is proportional to their concentrations. The amount of analyte element is given by the ratio of count rate of the characteristic peak in the sample to the rate in a known mass of the appropriate elemental standard irradiated under the same conditions.

Design of the facility has focused on three related topics. First, the high quality of the neutron beam and the low level of environmental background in the guide hall will allow closer sample-detector spacing, resulting in higher counting efficiency and better sensitivity, especially in the energy region below $1 \mathrm{MeV}$. Second, the high count rates possible with this high efficiency ( $>50 \mathrm{k}$ counts per sec) can be measured without loss of quality with recent advances in instrumentation. Finally, the improved efficiency will make attractive the use of $\gamma-\gamma$ and $\gamma$ conversion electron coincidence counting in analytical measurements, with considerably improved specificity in some cases.

Structural and shielding materials for this and neighboring instruments have been chosen as far as practicable to avoid generating a background of capture and decay gamma rays. Hydrogenous absorbers are avoided. The section of the beam tube adjacent to the sample position is made of boron-free glass. ${ }^{6} \mathrm{Li}$ is used wherever possible for collimators and absorbers, and antimony-free lead is used for gamma shielding [11]. As a result, the sensitivity for most elements is expected to be at least tenfold better than any with any thermal beam in existence. The detection limit for hydrogen is calculated to be about $1 \mu \mathrm{g}$. Characteristics are summarized in table 8.

Table 8. Prompt-gamma activation analysis characteristics

Location:

Max beam area and sample size:

Collimation:

Full-time access to beam.

Beam filtered through $\mathrm{Bi}$ and $\mathrm{Be}$ at $77 \mathrm{~K}$.

Expected reaction rate per atom at sample position:

Expected fast:

Neutron flux:

Expected gamma rate:

Gamma detector:
Neutron guide NG-7

$5 \times 5 \mathrm{~cm}$
6 Li glass

$2 \times 10^{8} \sigma_{0}$, where $\sigma_{0}$ is the

thermal neutron cross section.

$>1 \mathrm{eV}=<10^{-4} \mathrm{n} / \mathrm{cm}^{2}-\mathrm{s}$

$>1 \mathrm{MeV}=<10^{-1} \mathrm{n} / \mathrm{cm}^{2}-\mathrm{s}$

$<1 \mathrm{mR} / \mathrm{hr}$

High-resolution $\mathrm{Ge}$, designed for high-rate acquisition.

The computer control for apparatus and data acquisition is through an Ethernet-based ADCMCA and workstation. An automatic sample changer will be added in the future. The counting system is designed to handle multiple gamma detectors with Compton suppression. Future modifications will include multiparameter coincidence counting. 


\subsubsection{Cold Neutron Triple-Axis Spectrometer}

Two instruments of this category will be installed on guide tubes at the CNRF; the "SPINS" instrument is described later in this report. The design of the SPINS is completed, and fabrication is in progress.

Design features of the first instrument include [12]:

-- monochromator scattering angle from $30^{\circ}$ to $150^{\circ}$;

-- vertical focusing of the monochromator;

-- shielded filters between monochromator and sample (cold Be and PG);

-- sample scattering angles from $-150^{\circ}$ to $+150^{\circ}$;

-- shielded filters between sample and analyzer;

-- vertical focusing of the analyzer;

-- interchangeable collimators with angular acceptance between 10 and $60 \mathrm{~min}$ of arc between monochromator sample, sample-analyzer, and analyzer-detector;

-- the sample environment includes temperature control from $3 \mathrm{mK}$ to $2000 \mathrm{~K} \mathrm{deg}$., pressures to $10 \mathrm{kbar}$, and magnetic fields to 60 kilogauss; and

-- the minimum energy resolution is $\sim 10 \mu \mathrm{eV}$ at the elastic position with $0.6 \mathrm{~nm}$ neutrons.

\subsubsection{NIST Interferometer and Neutron Lifetime Experiment}

Two of the initial stations will be devoted to fundamental neutron physics, one of which will be for interferometry. A variety of interferometer geometries will be investigated for several different experiments. The anticipated experimental investigations will include long baseline neutron interferometry with separated crystals, delayed choice experiments and, possibly, a neutron Michelson-Morley experiment. Neutron interferometers are extremely sensitive to acoustic, seismic and thermal interference. Considerable attention has been paid to environmental isolation to insure optimal operation. However, implementation of these isolation features will defer commissioning of this instrument until 1992.

The other experimental station will provide an intense cold neutron beam for basic investigations in nuclear and particle physics. Anticipated experiments on this beam include studies involving neutron decay, nucleon-nucleon weak interactions and tests of basic symmetry principles. The initial experiment at this station will be a neutron lifetime measurement, which involves a collaboration between NIST, the University of Sussex (U.K.), the Central Bureau of Nuclear Measurement (Belgium), the Scottish Universities Research Reactor, Harvard University, and Los Alamos National Laboratory, expected to begin in early 1991.

\subsection{Second Phase Instrumentation}

It is planned that guides NG 1-4 will be installed beginning in late 1991. Experimental stations for these guides are, in some cases, in design or initial fabrication already. The current plan for instrumentation is described below. 


\subsubsection{The Center for High Resolution Neutron Spectroscopy 30-m SANS.}

The Center for High Resolution Neutron Scattering (CHRNS) includes a general purpose 30$\mathrm{m}$ small angle neutron scattering (SANS) instrument with polarized beam capability for the characterization of submicron structures of $1.0 \mathrm{~nm}$ to more than $100.0 \mathrm{~nm}$ sizes (table 9). The NSF is providing full funding for that instrument which will be a high resolution, wide scattering vector range spectrometer that combines and improves upon the best features of existing long flight path SANS instruments in the world. It will be located on a dedicated (NG-3) guide and is expected to be operational in 1991. This instrument will be very useful for the investigation of microstructures in various materials such as porous media, polymers/microemulsions, ceramics, biological systems, metals, etc. A set of user friendly software packages have been put together for both 30-m SANS instruments for data acquisition, instrument control, and data reduction.

Table 9. Characteristics of the NSF-SANS Instrument:

Source size:

Wavelength range:

Wavelength resolution:

Q-range:

Source to sample distance:

Sample to detector distance:

Detector:

Expected flux on sample:

Polarized beam option:

Two sample stages:
$6 \mathrm{~cm} \times 6 \mathrm{~cm}$ (neutron guide NG-3)

$0.4-2.0 \mathrm{~nm}$ (multidisk velocity selector)

7\%-30\% (continuously tunable)

$0.01-6.0 \mathrm{~nm}^{-1}$ (movable detector

inside flight path)

$.5 \mathrm{~m}-15 \mathrm{~m}$ (varied by moving neutron guides into the beam)

$1.20 \mathrm{~m}-13 \mathrm{~m}$

He-3 ILL type area detector with $64 \times 64$ elements

$1 \mathrm{~cm} \times 1 \mathrm{~cm}$ spatial resolution.

$10^{3}$ to $5 \times 10^{5} \mathrm{n} / \mathrm{cm}^{2} \mathrm{sec}$ depending on slit size and wavelength

use of transmission supermirror polarizer

main stage with 10 positions

Huber table for bulky sample environments

\subsubsection{The Spin-Polarized Inelastic Neutron Scattering (SPINS) Spectrometer.}

This facility is funded at the $50 \%$ level by NSF as part of CHRNS. SPINS, while sharing many mechanical features with the cold neutron triple-axis spectrometer (Section 4.1.7), is conceptually quite distinct [13]. The proposed machine is an innovative modification of a standard triple-axis spectrometer with the capability of measuring spin-dependent cross sections, as shown schematically in figure 8 .

The spectrometer will be capable of covering a range of incident neutron energies from 15 $\mathrm{meV}$ to $2 \mathrm{meV}$ with resolutions from $1 \mathrm{meV}$ down to about $10 \mu \mathrm{eV}$ and with tunable instrumental resolution. In order to decouple the dependence of the energy resolution and the angular divergence of the beam, the proposed spectrometer will utilize a novel energy-dependent spin flipping device in conjunction with a pair of polarizing supermirrors as an energy analyzer and/or monochromator preceding the sample as desired. The energy-dependent flipper is of the type first proposed by G. M. Drabkin [14]. Using this monochromating device, a very high energy 


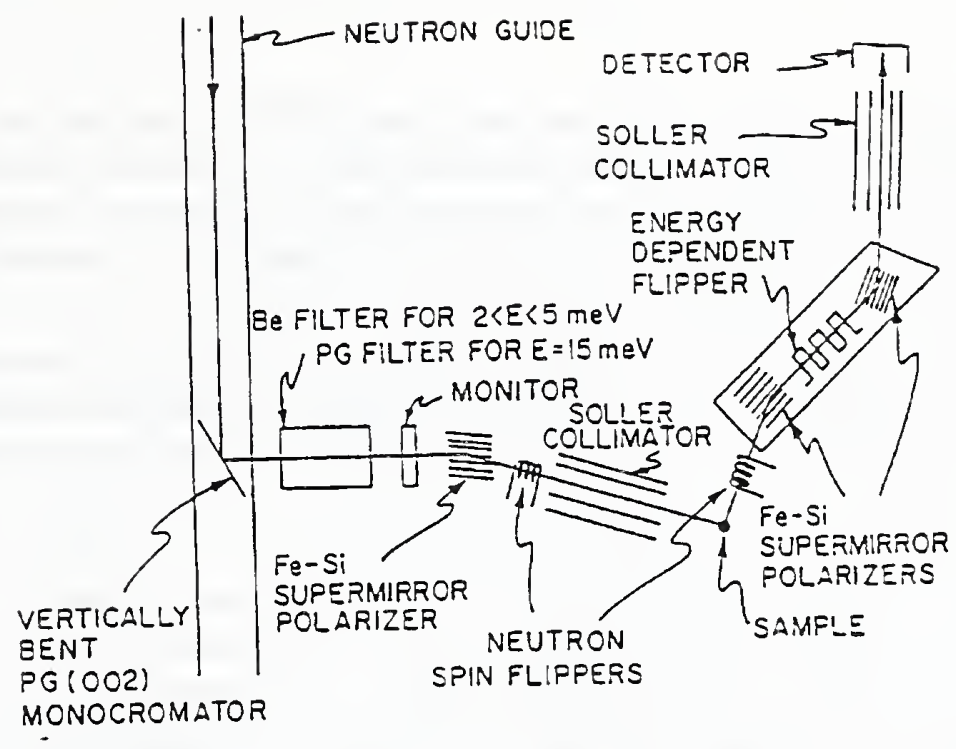

Figure 8. SPINS spectrometer.

resolution can be obtained even for a considerably divergent beam with a corresponding gain in intensity. The resolution function of the spectrometer can therefore be tuned for a particular experiment. A performance comparison with a typical triple-axis instrument is indicated in table 10.

Table 10. Triple-axis and SPINS ${ }^{\mathrm{a}}$ spectrometers comparison

\begin{tabular}{cll|lll}
\multicolumn{2}{c|}{ Flipper } & \multicolumn{3}{|c}{ Triple-axis Spectrometer $^{\mathrm{b}}$} \\
\hline & & & & \\
$\mathrm{M}^{\mathrm{c}}$ & Intensity & FWHM(meV) & Collimation $^{\mathrm{d}}$ & Intensity & FWHM(meV) \\
50 & 1.0 & 0.32 & $\left(80^{\prime}\right)^{4}$ & 1.0 & 0.308 \\
100 & 0.5 & 0.16 & $\left(40^{\prime}\right)^{4}$ & 0.1 & 0.154 \\
200 & 0.25 & 0.08 & $\left(20^{\prime}\right)^{4}$ & 0.033 & 0.077 \\
400 & 0.125 & 0.04 & $\left(10^{\prime}\right)^{4}$ & 0.0005 & 0.039
\end{tabular}

${ }^{a}$ In this case, an elastic scattering comparison for a single energy-dependent flipper at $\mathrm{E}=5 \mathrm{meV}$ and $80^{\prime}$ collimation.

${ }^{b} \mathrm{PG}(002)$ monochromator and analyzer with $30^{\prime}$ mosaics.

${ }^{c}$ Number of current sheets in flipper (see ref. 13).

${ }^{\mathrm{d}}$ All four collimators equal.

It should be emphasized that the proposed spectrometer is designed for both polarized and unpolarized beam experiments. The energy-dependent analyzer device utilizes the neutron spin but does not require that the sample have a scattering cross section that is spin-dependent. Furthermore, the spectrometer will be designed to be completely flexible in choice of either PG or energy-dependent flipper and pair of supermirrors at both the monochromator and analyzer positions. 


\subsubsection{High Resolution Time-of-Flight (HR-TOF) Spectrometer}

The principal purpose of the high resolution time-of-flight spectrometer will be to provide high energy resolution using relatively short wavelength neutrons. In this way we shall be able to extract important spatial information about the dynamical processes which account for the spectra observed in a given experiment. Typically, we expect to achieve about $12 \mu \mathrm{eV}$ energy resolution using $0.6 \mathrm{~nm}$ neutrons, corresponding to a $\mathrm{Q}$ range up to $\sim 18 \mathrm{~nm}^{-1}$. The spectrometer is also designed to be highly versatile, in terms of wavelength and energy resolution, so that rapid measurements with relatively poor resolution can be performed prior to more definitive high resolution studies. The instrument will be unsurpassed in performance anywhere in the world.

The high resolution time-of-flight spectrometer will use two pairs of counter-rotating disk choppers to produce a pulsed beam of monochromatic neutrons at the sample position [15]. Two additional choppers will remove order contamination, and a seventh chopper will be used to reduce the burst frequency in order to minimize data analysis problems due to frame overlap at the detector. The 58.0-cm diam high-strength aluminum chopper disks will run on magnetic bearings, with phase control good to $250 \mathrm{~ns}$ at rotational speeds as high as $20,000 \mathrm{rpm}$. The height of the beam will be $10.0 \mathrm{~cm}$, and a choice of three distinct slot widths will be available, depending on the desired resolution. We shall employ a multiply-channeled guide in order to optimize intensity at each choice of chopper slot width [16]. Estimated characteristics are summarized in table 11 .

Table 11. New TOF estimated performance

$\underline{\text { Resolution }(\mu \mathrm{eV})}$

$\begin{array}{lcc}\text { high } & \text { medium } & \text { low } \\ \text { resolution mode } & \text { resolution mode } & \text { resolution mode }\end{array}$

$\begin{array}{lccc}0.2 \mathrm{~nm} & 270 & 650 & 1300 \\ 0.4 \mathrm{~nm} & 35 & 80 & 160 \\ 0.6 \mathrm{~nm} & 12 & 25 & 50 \\ 0.8 \mathrm{~nm} & 6 & 11 & 21\end{array}$

$\begin{array}{cccc}\frac{}{\text { Intensity on }} & & & \\ \frac{\text { sample }}{(\mathrm{n} / \mathrm{s})} & & & \\ & 3 \times 10^{3} & 9 \times 10^{4} & 7 \times 10^{5} \\ 0.2 \mathrm{~nm} & 4 \times 10^{3} & 1.2 \times 10^{5} & 1 \times 10^{6} \\ 0.4 \mathrm{~nm} & 1.2 \times 10^{3} & 4 \times 10^{4} & 3 \times 10^{5} \\ 0.6 \mathrm{~nm} & 5 \times 10^{2} & 1.5 \times 10^{4} & 1.2 \times 10^{5}\end{array}$

The instrument is to be located on guide NG-1, which is planned to have supermirror-coated top and bottom surfaces in order to increase the intensity at the sample. An installation date in 1992 is anticipated. 


\subsubsection{Backscattering Spectrometer}

The cold neutron backscattering spectrometer will be the first spectrometer with ultra-high energy resolution to be built in the United States. The excellent resolution, $\propto 0.5 \mu \mathrm{eV}$, is achieved by reflecting the neutrons from perfect $\mathrm{Si}$ monochromator and analyzer at a Bragg angle of $\propto 90^{\circ}$. The major drawback of this approach is the low intensity due to the narrow energy slice which is accepted and to the small divergence of the incident beam imposed by the guide. Since the narrow energy slice is necessary to obtain the desired resolution, the only way to improve the intensity is to increase the divergence of the incident beam. Several features are planned in order to accomplish this. First the instrument will be placed on a ${ }^{58} \mathrm{Ni}$ guide; supermirror coatings on the top and bottom of the guide are being considered. There will also be a converging supermirror nose to compress the beam from $6 \times 15 \mathrm{~cm}^{2}$ to $\sim 3 \times 3 \mathrm{~cm}^{2}$, necessary because the sample size has a second-order affect on the resolution.

An innovative feature intended to increase the divergence of the incident beam is the implementation of the phase-space transform idea of Schelten and Alefeld [17]. Here a crystal with a relatively large mosaic is placed on a disk chopper so that the crystal moves perpendicularly to the average scattering vector. Then neutrons that have larger Bragg angles than the nominal one are Doppler shifted to larger energies and vice versa; i.e., neutrons that are moving too slowly are sped up and those moving too fast are slowed down. Simulations [18] have shown that a gain of a factor of 5-6 may be possible with this technique.

Another important feature planned for the backscattering spectrometer which will reduce the counting time for some experiments is a hydraulic Doppler drive for varying the incident energy distribution. This device, pioneered at Julich, allows the experimenter to vary the incident energy distribution so that the majority of time can be spent in a region of particular interest; e.g., in the vicinity of a rotational tunneling line. In addition, this device will extend the dynamical range of the instrument out to at least $100 \mu \mathrm{eV}$, if the experimenter chooses to do so. With the inclusion of these features which should increase the neutron current density on the sample to $5 \times 10^{4} \mathrm{n} / \mathrm{sec}-\mathrm{cm}^{2}$ and provide a great deal of flexibility to the researcher, this spectrometer will open up a wide range of experiments in condensed matter chemistry and physics that are at present impossible to perform in the United States. Characteristics are summarized in table 12 .

Table 12. Backscattering instrument

Monochromator:

Analyzer:

Wave length:

Energy resolution:

Energy regime:

Time regime:

Q - range:

Monochromator-to-sample distance:

Sample-to-analyzer distance:

Maximum sample size:

Estimated flux at sample:
Si(111) crystals, mounted on hydraulic Doppler drive

$\mathrm{Si}(111)$ crystals

$0.627 \mathrm{~nm}$

$0.5 \mu \mathrm{eV}\left(0.004 \mathrm{~cm}^{-1}\right)$ (FWHM)

$0.2 \mu \mathrm{eV}$ up to $100 \mu \mathrm{eV}$

$2 \times 10^{-8} \mathrm{sec}$ to $4 \times 10^{-11} \mathrm{sec}$

1.0 to $18.0 \mathrm{~nm}^{-1}$

probably $2 \mathrm{~m}$

probably $2 \mathrm{~m}$

probably $3 \times 3 \mathrm{~cm}^{2}$

$5 \times 10^{4} \mathrm{n} / \mathrm{cm}^{2} / \mathrm{sec}$ (current cold source) 


\subsubsection{Grazing-Angle Neutron Diffractometer}

The recent development of synchrotron sources has led to a broad application of the method of grazing-angle diffraction as an $\mathrm{x}$-ray structural probe of surfaces and interfaces. The comparatively low flux of conventional neutron sources had, until recently [19-20], prevented a similar use of the technique in neutron experiments. The essence of the grazing-angle diffraction technique is the excitation of a diffracted beam under conditions of total external reflection of the incident beam. In figure 9 the wave-vectors external to the crystal in the grazing-angle geometry are shown. A neutron beam $(\overrightarrow{\mathrm{k}})$ strikes the sample at an angle $\phi$ with respect to the surface and is specularly reflected $\left(\overrightarrow{\mathrm{k}}_{\mathrm{S}}, \phi\right)$; the sample is oriented such that an inplane reflection $\left(\vec{k}_{G}\right)$ is excited at glancing angle $\phi_{G}$, where $\vec{G}$ is in the plane of the surface. The total reflection occurring simultaneously with the diffraction process ensures that the diffracted intensity originates in that portion of the sample which lies close to the surface.

The grazing-angle diffractometer to be installed in the CNRF is currently in the conceptual design stage.

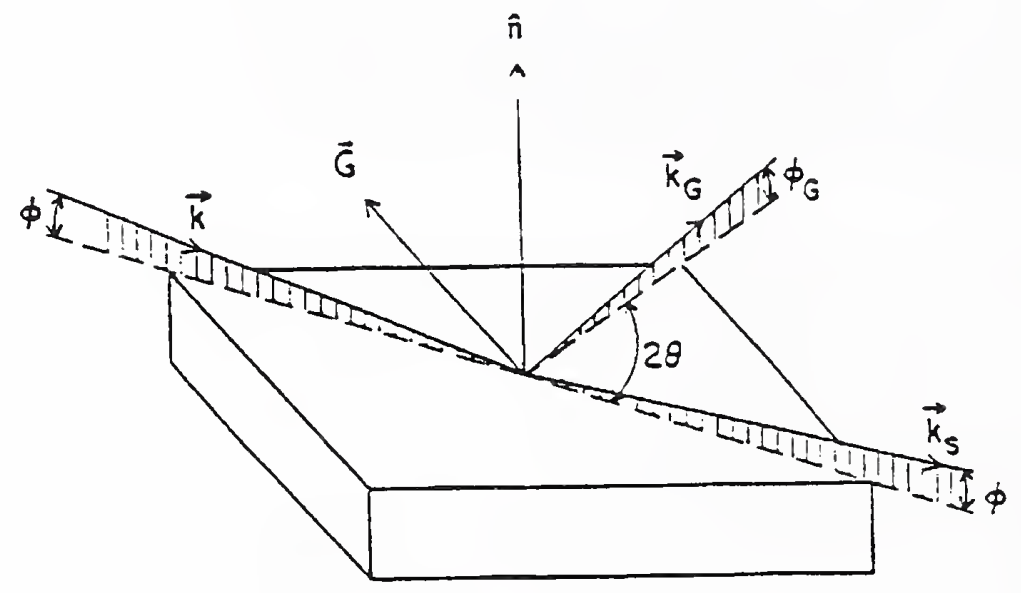

Figure 9. Grazing-angle geometry.

\section{Institutional Considerations}

This facility is located within the Materials Science and Engineering Laboratory, which comprises a large, multidisciplinary program of research in Polymers, Ceramics, Metallurgy, Fracture and Deformation, and Non-Destructive Evaluation, as well as the Reactor Radiation Division. The Reactor facilities are used by all of these groups, and by many other major organizations at NIST, such as the Chemical Science and Technology Laboratory, the Physics Laboratory, and the Ionizing Radiation Division, thus providing an excellent research environment. NIST has a Cyber 205 computer for large scientific calculations, and the Cold Neutron Research Facility has a network of data acquisition and analysis computers which are linked to the main computer. The Gaithersburg site is well-equipped to handle conferences and visitors, and hosted over 100 conferences in the past year. NIST has in place long-standing 
programs for guest scientists, industrial research associates, visiting faculty and students, and post-doctoral appointments. NIST is located less than one hour's drive from three major airports, and is in the immediate vicinity of a wide range of motels, housing, restaurants, and shopping facilities.

\section{Staff}

The scientific staff currently working on instrument design for the Cold Neutron Research Facility and their areas of responsibilities are listed below. All telephone numbers are area code 301 , or $879-\mathbf{x x x x}$ for FTS.

J. Michael Rowe (975-6209)

John J. Rush (975-6231)

Ivan G. Schröder (975-6212)

John R. D. Copley (975-5133)

Terrence Udovic (975-6241)

Charles J. Glinka (975-6242)

Boualem Hammouda (975-3961)

Susan Krueger (975-6734)

Charles F. Majkrzak (975-5251)

Dan Neumann (975-5252)

Sushil Satija (975-5250)

Richard Lindstrom (975-6281)

Norman F. Berk (975-6224)

Gregory Downing (975-6286)

George Lamaze (975-6202)

Geoffrey Greene (975-4842)

Samuel F. Trevino (975-6227)

John Ankner (975-6219)

Robert E. Williams (975-6876)
- Chief, Reactor Radiation Division

- Neutron Scattering Group Leader

- neutron guides and overall instrumentation

- time-of-flight spectrometry

- small angle scattering instruments

- spin polarized inelastlc

- supermirror development

- backscattering spectrometer

- neutron reflectometry

- prompt gamma-ray spectrometer

- cold neutron analytical techniques

- neutron depth profiling

- neutron interferometry

- triple-axis spectrometer

- cold source design 


\section{References}

[1] Prask, H. J. The reactor and cold neutron research facility at NIST. Neutron News, 1(1): 9-13; 1990.

[2] O'Connor, C., ed. NIST reactor: summary of activities July 1989 through June 1990. NIST Tech. Note 1285 (1990).

[3] Reviewed by Maier-Leibnitz, H., and Springer, T., Reactor Sci. Tech. 17, 217 (1963).

[4] Major Facilities for Materials Research and Related Disciplines, presentation to the Major Materials Facilities Committee, National Research Council, report published by the National Academy Press, Washington, D.C. 1984.

[5] Astruc, J. M. and Gobrecht, K. H. "Cryogenics of Cold Neutron Sources," Inst. Laue-Langevin Report, 1987.

[6] Glinka et al., NIST Tech Note 1257, p. 136, January 1989.

[7] Glinka, C. J. et al. High resolution small angle scattering spectrometer. NIST Tech. Note 1285, C. O'Connor, ed., December 1990.

[8] Anastasiadis, S. I.; Russell, T. P.; Satija, S. K.; Majkrzak, C. F. Phys. Rev. Lett. $\underline{62}$, 1852 (1989); J. Chem. Phys. (in press).

[9] Lamaze, G. P.; Downing, R. G.; Langland, J. K.; Littrell, K. C. Cold neutron depth profiling. NIST Tech. Note 1285 (1990), pp. 99-100.

[10] R. M. Lindstrom, private communication.

[11] Stone, C. A.; Zeisler, R.; Blackburn, D. H.; Kauffman; Cranmer, D. C. ${ }^{6}$ Li-doped silicate glass for thermal neutron shielding. NIST Tech Note 1285 (1990), p. 116.

[12] Trevino, S. F. NIST Tech. Note 1272, p. 200 (1989).

[13] Majkrzak, C. F.; Glinka, C. J.; Satija, S. K. SPIE Conf. Proc. No. 983, to be published.

[14] G. M. Drabkin, Sov. Phys. JETP 43, 1107 (1962).

[15] Copley, J. R. D. Nucl. Inst. Meth. (in press); see also NIST Tech Note 1285 (1990), pp. 100, 101, 103.

[16] Copley, J. R. D. Nucl. Inst. Meth. A291, 519 (1990).

[17] Schelten, J. and Alefeld, B.; in Proc. Workshop on Neutron Scattering Instrumentation for SNQ, Maria Laach, 3-5 September 1984, Scherm, R. and Stiller, H. H., eds. report Jül-1954 (1984).

[18] Neumann, D. A.; in NBS Reactor: Summary of Activities July 1987 Through June 1988, O'Connor, C., ed. NIST Tech Note 1257, p. 141.

[19] Ankner, J. F.; Zabel, H.; Neumann, D. A.; Majkrzak, C. F. Phys. Rev. B40 792 (1989).

[20] Ankner, J. F.; Zabel, H.; Neumann, D. A.; Majkrzak, C. F.; Dura, J. A.;Flynn, C. P. J. de Phys. $\underline{50}$ C7-189 (1989). 


\begin{tabular}{|c|c|c|}
\hline \multirow[t]{3}{*}{$\begin{array}{l}\text { NIST.114A } \\
\text { (REV. 3-90) }\end{array}$} & \multirow{3}{*}{$\begin{array}{l}\text { U.S. DEPARTMENT OF COMMERCE } \\
\text { NATIONAL INSTITUTE OF STANDARDS AND TECHNOLOGY } \\
\text { BIBLIOGRAPHIC DATA SHEET }\end{array}$} & $\begin{array}{l}\text { 1. PUBLCATION OA REPORT MUMBER } \\
\text { NISTIR } 4527 \\
\text { 2. PERFORMIMO ORQANIZATIOM REPORT MUMBER }\end{array}$ \\
\hline & & 2. PERFORMIMG ORGANIZATION REPOAT NUMBEA \\
\hline & & $\begin{array}{l}\text { 3. PUBLCATION DATE } \\
\text { MARCH } 1991\end{array}$ \\
\hline
\end{tabular}

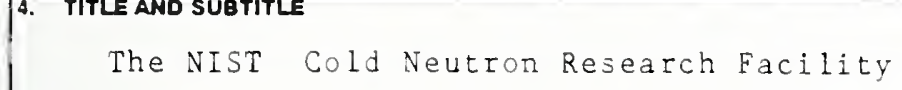

6. PERFORMING ORGANIZATION (IF JOINT OR OTHER THAN NIST, SEE INSTRUCTIONS) U.S. DEPARTMENT OF COMMERCE NATIONAL INSTITUTE OF STANDARDS AND TECHNOLOGY GAITHERSBURG, MO 20890

\section{CONTRACT/ORANT NUMBEA \\ 8. TYPE OF REPORT AND PEAIOD COVERED}

9. SPONSORINO ORGANIZATION NAME AND COMPLETE ADDRESS (STREET, CITY, STATE, ZIP)

10. SUPPLEMENTARY NOTES

11. ABSTRACT (A 200-WOAD OA LESS FACTUAL SUMMARY OF MOST SIGNIFICANT INFOAMATION. IF DOCUMENT INCLUDES A SIGNIFICANT BIBLOGAAPHY OR UTERATURE SURVEY, MENTION IT MERE.)

The NIST reactor, which is one of the major research reactors in the United States, had a provision for a large volume cold neutron moderator built into it when it was constructed. Utilizing this capability, the Department of Commerce and NIST have begun a project to develop a major national facility for cold neutron research, the cold Neutron Research Facility (CNRF). This \$3OM project will, when fully completed, provide at least fifteen new experimental stations for use by U.S. researchers, with capability currently unavailable in this country. It will be operated as a National Facility, open to all qualified researchers on the basis of scientific merit. One-third of the experimental stations will be provided by sources outside of NIST.

12. KEY WORDS (6 TO 12 ENTAIES; ALPHABETICAL ORDER; CAPITALZE OMLY PROPER MAMES; AMD SEPARATE KEY WORDS OY SEAICOLONS) materials science; national facilities research center; neutron chemical analysis; neutron instrumentation; neutron scattering; research reactors.

FOR OFFICIAL DISTRIBUTION. DO NOT RELEASE TO MATIOMAL TECHMICAL INFORMATION SERVICE (NTIS).

ORDER FROM SUPERINTENDENT OF DOCUMENTS, U.S. GOVERMMENT PAINTING OFFICE, WASHINOTON, DC 20402.

ORDER FAOM NATIONAL TECHMICAL INFORMATION SERVCE (NTIS), SPRINGFIELD, VA 2161. 

